\title{
Role of enteral nutrition in nonthyroidal illness syndrome: a retrospective observational study
}

\author{
Ranran Li, Jianan Ren*, Qin Wu, Gefei Wang, Xiuwen Wu, Jun Chen, Guanwei Li, Zhiwu Hong, Huajian Ren,
} Yunzhao Zhao and Jieshou Li

\begin{abstract}
Background: The nonthyroidal illness syndrome (NTIS) is prevalent among patients with enterocutaneous fistula and is associated with poor outcomes. The present study aimed to explore the role of enteral nutrition (EN) therapy on thyroid function among patients with enterocutaneous fistula and NTIS.

Methods: We conducted a retrospective observational study among patients with enterocutaneous fistula between January 2013 and April 2014. All enrolled patients received EN therapy. Thyroid function and other parameters were measured.

Results: After administration of 4 weeks of EN therapy, NTIS was resolved in 66 patients (Group A), while it persisted in 14 patients (Group B). The overall treatment success rate was $82.50 \%$. There were no significant differences between groups A and B at baseline for all parameters, except for the time from admission to start of EN therapy. The logistic analysis revealed that the time from admission to start of EN therapy was a significant independent indicator for achieving resolution of NTIS in our cohort.

Conclusions: This retrospective observational cohort study demonstrated that EN therapy can aid in the resolution of NTIS among patients with enterocutaneous fistula. These findings confirm the benefit of EN in the treatment of enterocutaneous fistula.
\end{abstract}

Keywords: Nonthyroidal illness syndrome, Enterocutaneous fistula, Thyroid function, Enteral nutrition

\section{Background}

Changes in the endocrine system that result from critical illnesses can cause multiple dysfunctions [1]. Also known as the euthyroid sick syndrome, the nonthyroidal illness syndrome (NTIS) commonly affects patients with enterocutaneous fistula $[1,2]$. This syndrome is characterized by alterations in thyroid function, which are commonly reflected as low serum triiodothyronine (T3) and normal to low thyroxine (T4). Studies have suggested that low levels of thyroid hormones are predictors of poor outcome in sepsis and critical illness [3]. In our previous study, we reported an association between NTIS and poor outcome

\footnotetext{
* Correspondence: jiananr@gmail.com

The work was supported by grants from the National Nature Science Foundation of China (81270478).

Department of General Surgery, Jinling Hospital, Medical School of Nanjing University, 305 East Zhong Shan Road, Nanjing 210002, China
}

among patients with enterocutaneous fistula, indicating the clinical importance of these alterations [1].

To date, the pathogenesis of these endocrine alterations in NTIS is not fully understood. Previous studies have reported several approaches for improving thyroid function in different patient populations with NTIS [4-6]. Some studies suggested the association between nutritional deficiency and NTIS, indicating a potential role of enteral nutrition (EN) therapy in resolving NTIS [7, 8]. Conversely, other studies reported that underlying illness plays a key role in NTIS, suggesting that EN therapy would not be expected to aid in the resolution of the thyroid abnormalities $[9,10]$. Because the prevalence of NTIS among patients with enterocutaneous fistula is increasing, we conducted a retrospective observational study to investigate the role of EN therapy in the resolution of NTIS.

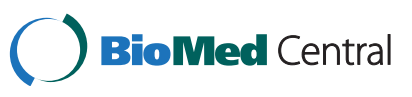

(c) $2015 \mathrm{Li}$ et al. Open Access This article is distributed under the terms of the Creative Commons Attribution 4.0 International License (http://creativecommons.org/licenses/by/4.0/), which permits unrestricted use, distribution, and reproduction in any medium, provided you give appropriate credit to the original author(s) and the source, provide a link to the Creative Commons license, and indicate if changes were made. The Creative Commons Public Domain Dedication waiver (http:// creativecommons.org/publicdomain/zero/1.0/) applies to the data made available in this article, unless otherwise stated. 


\section{Methods}

\section{Ethics statement}

This retrospective, observational cohort study was conducted in accordance with the principles of good clinical practice and the Declaration of Helsinki. The study protocol was reviewed and approved by the Institutional Review Board at Jingling Hospital. Informed consent was not obtained as patient records and information were anonymized and de-identified prior to the study.

\section{Patients and study design}

Based on a detailed medical chart review, we primarily enrolled consecutive patients with enterocutaneous fistula admitted between January 2013 and April 2014. The standard values of the variables assessed at our hospital are as follows: free triiodothyronine (FT3), 3.8-6.5 pmol/L; total triiodothyronine (TT3), $1.23-3.07 \mathrm{nmol} / \mathrm{L}$; free thyroxin (FT4), 7.9-17.2 pmol/L; total thyroxin (TT4), 71-161 nmol/L; and thyroid stimulating hormone (TSH), 0.3-4.5 mU/L.

The criteria for NTIS applied in our study were as follows: (1) FT3 level less than $3.8 \mathrm{pmol} / \mathrm{L}$ and (2) TSH upper normal limit of $4.5 \mathrm{mU} / \mathrm{L}[2,10]$. In our department, all patients underwent thyroid homeostasis measurements upon admission for NTIS scanning, and a thyroid test every week to evaluate the thyroid function.
Records of patients with NTIS at admission were primarily collected. The exclusion criteria were as follows (1) current use of EN, thyroid hormone and antithyroid drugs at admission; (2) history of coronary artery disease, myocardial infarction or cerebral infarction in the past month upon admission; (3) pregnancy or lactation; (4) a previous history of thyroidal, hypophyseal or hypothalamic disease; (5) age less than 18; (6) craniocerebral injury; (7) end-stage advanced malignant tumor; (8) medication history of thyroid hormone or antithyroid drugs; (9) and intracranial infection or hemorrhage in the past month. After excluding patients, clinical data of the remaining patients were collected to constitute our cohort. The observational period was limited to 4 weeks. The time point at admission was defined as week 0 .

The primary outcome of our study was defined as the resolution of NTIS at week 4 after admission. We defined in this study that patients whose FT3 level is above $3.8 \mathrm{pmol} / \mathrm{L}$ at week 4 are those who recovered from NTIS. At the end of the study, patients who experienced resolution of NTIS in this cohort were assigned to Group A while others were assigned to Group B.

\section{EN therapy}

In our department, the EN used for patients with enterocutaneous fistula was Peptisorb Liquid (Enteral Nutrition

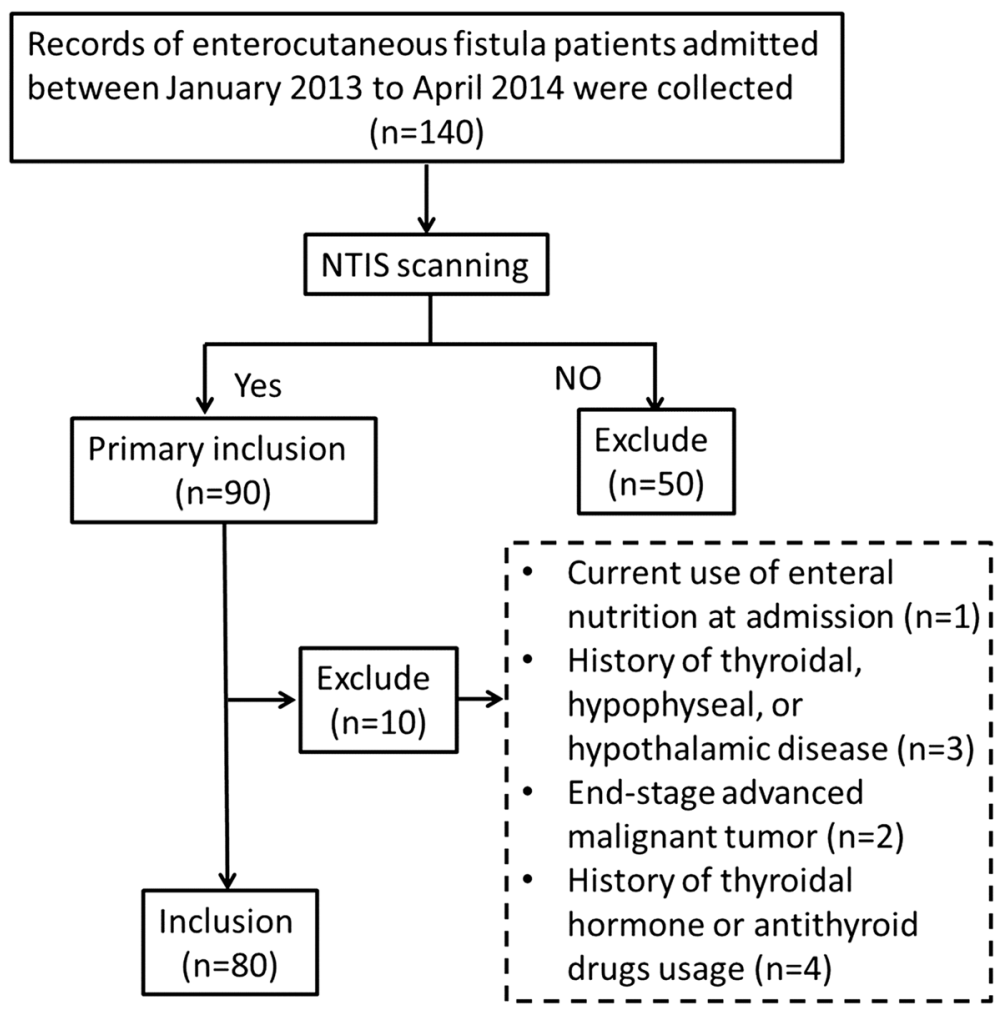

Fig. 1 Flowchart of the current study. In total, 90 consecutive patients with NTIS were retrospectively enrolled from 140 patients with enterocutaneous fistula. Ten patients were excluded based on the exclusion criteria checking, and 80 patients were finally included 
Suspension; Nutricia Company, Amsterdam, Holland). Once the output of intestinal fluid was limited $(<200 \mathrm{ml} / \mathrm{L})$ and patients were satisfactorily maintained on enteral feeding, EN was gradually introduced to reach full feeding. The EN therapy in our study was conducted as described in our previous study [11]. Briefly, EN was prescribed through a nasogastric or nasointestinal tube. The formula contained $1 \mathrm{cal} / \mathrm{mL}$ and had $500 \mathrm{kcal} /$ bottle. The energy requirements were calculated using Long's modified equation according to the usual body weight. No oral foods or fluids (except for water and weak tea) were allowed. The nutrition regimen during the study period remained almost unchanged.

\section{Data collection}

For each enrolled patient, the following data were collected from the medical record: primary diseases, fistula location, underlying disease, Acute Physiology and Chronic Health Evaluation Score (APACHE II), time for initiation of enteral nutrition upon admission, white blood cell count (WBC), C-reactive protein (CRP), red blood cell count ( $\mathrm{RBC}$ ), platelet count (PCs), glutamic-pyruvic transaminase (GPT) and blood urine creatinine (Cr), FT3, TT3, FT4, TT4 and TSH. Baseline characteristics, including age and sex, were also collected.

In our department, venous blood for all laboratory tests was drawn between $5 \mathrm{am}$ and $6 \mathrm{am}$. Serum indexes, including WBC, CRP, RBC, PCs, Cr, GPT FT3, TT3, FT4, TT4 and TSH were measured at least once a week to monitor the patients' status. Laboratory values were calculated within $2 \mathrm{~h}$ after blood collection.

\section{Statistical analysis}

Demographic data and laboratory parameters were summarized by frequency for categorical variables and means \pm standard deviation (SD). The proportions were compared with chi-square test or Fisher's exact test. Continuous variables were tested by means of the $t$-test with normal distribution or Wilcoxon rank-sum test with non-normal distribution. A logistic analysis was performed to assess the influence of each variable on treatment success rate. Survival analysis was conducted, and statistical analyses were performed with GraphPad Prism Software (version 5.01; GraphPad, San Diego, CA, USA) and SAS software (SAS 9.1.3; SAS Institute Inc., Cary, NC, USA). A P value $<0.05$ was considered statistically significant.

\section{Results}

\section{Patient characteristics}

In total, 140 consecutive patients with enterocutaneous fistula were admitted to our department from January 2013 and April 2014. We retrospectively enrolled 90 consecutive patients with enterocutaneous fistula who met the NTIS criteria as primary inclusion. Ten patients met the exclusion criteria and were excluded from the study. Therefore, the final study cohort consisted of 80 patients (Fig. 1).

The general clinical characteristics of the study group at admission are presented in Table 1 . Among the 80 cases, there were 58 males and 22 females (male-tofemale ratio, 2.64:1). Patient had a mean $( \pm S D)$ age of $48.05 \pm 13.43$ years. The most common causes for enterocutaneous fistula development in our study were trauma and surgical complications. The most common location of enterocutaneous fistula was the small bowel. A total of 24 patients had a positive history of diabetes mellitus, and 12 had chronic obstructive pulmonary diseases. The time from admission to start of EN therapy varied during our observational period. During the EN treatment, 8 patients $(9.76 \%)$ had diarrhea caused by the EN infusion, and symptoms were managed as stated in the medical records. None of the patients

Table 1 General clinical condition of the study group at admission

\begin{tabular}{|c|c|}
\hline Parameters & All subjects $(N=80)$ \\
\hline Gender (Male, n \%) & $58(72.50 \%)$ \\
\hline Age (yrs, mean $\pm S D)$ & $48.05 \pm 13.43$ \\
\hline \multicolumn{2}{|l|}{ Severity scores, mean $\pm S D$} \\
\hline APACHE II score & $16.27 \pm 2.05$ \\
\hline \multicolumn{2}{|l|}{ Primary diagnosis (n \%) } \\
\hline Trauma/Surgery complication & $50(62.50 \%)$ \\
\hline IBD & $16(20.00 \%)$ \\
\hline Pancreatitis & $6(7.50 \%)$ \\
\hline Others & $8(10.00 \%)$ \\
\hline \multicolumn{2}{|l|}{ Fistula location } \\
\hline Duodenum & $12(15.00 \%)$ \\
\hline Colon & $16(20.00 \%)$ \\
\hline Small bowel & $32(40.00 \%)$ \\
\hline Multiple viscera $^{a}$ & $20(25.00 \%)$ \\
\hline \multicolumn{2}{|l|}{ Underlying disease, n ( \%) } \\
\hline Untreated cancer & $8(10.00 \%)$ \\
\hline DM & $24(30.00 \%)$ \\
\hline COPD & $12(15.00 \%)$ \\
\hline None & $36(45.00 \%)$ \\
\hline \multicolumn{2}{|c|}{ Time for initiation of enteral nutrition, n (\%) } \\
\hline$<7$ day & $20(25.00 \%)$ \\
\hline 7-14 days & $30(37.50 \%)$ \\
\hline 15-21 days & $22(27.50 \%)$ \\
\hline$>22$ days & $8(10.00 \%)$ \\
\hline
\end{tabular}

IBD inflammatory bowel diseases, DM diabetes mellitus, COPD chronic obstructive pulmonary diseases, $L O S$ length of stay, IQR interquartile range ${ }^{a}$ Multiple viscera includes small bowel/colon, duodenum/small bowel or pancreas/duodenum/small bowel 
discontinued EN because of poor tolerance to EN therapy during the study period. No mortality occurred among the cohorts.

\section{Changes in thyroid function}

Figure 2 and Additional file 1: Tables S1 shows the changes of thyroid function in this cohort during the observational period. During our observational period, serum FT3 concentrations were significantly increased, from $3.02 \pm 0.138$ at the baseline to $4.13 \pm 0.052$ in the last week $(p<0.001)$, while serum level of FT4, TT4 and TSH kept stable during our observation.

According to our definition, 66 patients experienced resolution of NTIS (Group A) while 14 patients did not (Group B). The overall treatment success rate for both groups was $82.50 \%(66 / 80)$. Table 2 presents the general clinical condition of both groups. The time from admission to start for EN therapy was significantly different between Groups A and B. Thyroidal function changes between those two groups in our study were displayed in Fig. 2 and Additional file 2: Table S2. Serum FT3 and TT3 level increased significantly faster in group A compared with those in group B. At the end of the second week after admission, serum FT3 and TT3 in group A were significantly higher than those in group $\mathrm{B}$.

The logistic regression were performed with variables that associated with treatment success, respectively, in our study, including age, gender, primary diagnosis, fistula location, underlying disease, APACHEIIscore and time for initiation of enteral nutrition, to demonstrate their association with treatment success. Table 3 revealed that initial time of EN was a significant independent indicator with treatment success in our cohort.
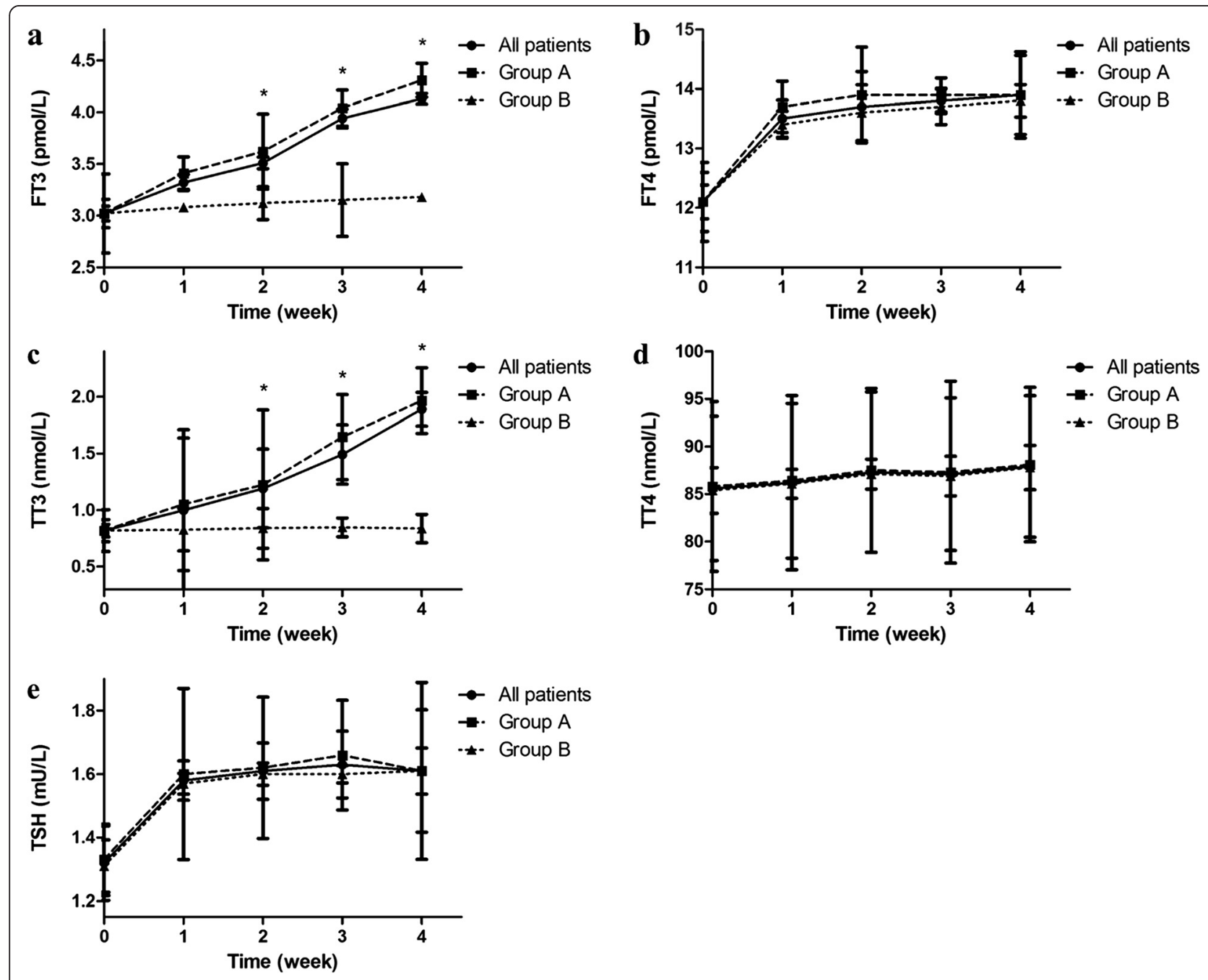

Fig. 2 Changes of thyroidal function during the observational period. Serum (a) FT3 and (c) TT3 kept significantly increasing in group A compared with group B while other index $[(\mathbf{b}) \mathrm{FT} 4$, (d) TT4 and (e) TSH] remained stable. (* indicated a significant difference between group A and group B) 
Table 2 General clinical condition of the group A and group B at admission

\begin{tabular}{|c|c|c|c|}
\hline Parameters & Group A $(N=66)$ & Group B $(N=14)$ & $P$ \\
\hline Gender (Male, n \%) & $48(72.72 \%)$ & $10(71.43 \%)$ & 0.944 \\
\hline Age (yrs, mean $\pm S D)$ & $47.69 \pm 13.03$ & $48.71 \pm 15.17$ & 0.708 \\
\hline \multicolumn{4}{|l|}{ Severity scores, mean \pm SD } \\
\hline APACHE II score & $15.64 \pm 1.29$ & $16.47 \pm 2.87$ & 0.248 \\
\hline Primary diagnosis (n \%) & & & 0.679 \\
\hline Trauma/Surgery complication & $44(66.67 \%)$ & $6(42.86 \%)$ & \\
\hline $\mathrm{IBD}$ & $12(18.18 \%)$ & $4(28.57 \%)$ & \\
\hline Pancreatitis & $4(6.06 \%)$ & $2(14.29 \%)$ & \\
\hline Others & $6(9.09 \%)$ & $2(14.29 \%)$ & \\
\hline Fistula Location & & & 0.139 \\
\hline Duodenum & $10(15.15 \%)$ & $2(14.29 \%)$ & \\
\hline Colon & $16(24.24 \%)$ & $0(0.00 \%)$ & \\
\hline Small bowel & $28(42.42 \%)$ & $4(28.57 \%)$ & \\
\hline Multiple viscera $^{a}$ & $12(18.18 \%)$ & $8(57.14 \%)$ & \\
\hline Underlying disease, n (\%) & & & 0.634 \\
\hline Untreated cancer & $6(9.09 \%)$ & $2(14.29 \%)$ & \\
\hline DM & $20(30.30 \%)$ & $4(28.57 \%)$ & \\
\hline COPD & $12(18.18 \%)$ & $0(0.00 \%)$ & \\
\hline None & $28(42.42 \%)$ & $8(57.14 \%)$ & \\
\hline Time for initiation of enteral nutrition, $\mathrm{n}(\%)$ & & & 0.013 \\
\hline$<7$ day & $18(27.27 \%)$ & $2(14.29 \%)$ & \\
\hline 7-14 days & $28(42.42 \%)$ & $2(14.29 \%)$ & \\
\hline $15-21$ days & $18(27.27 \%)$ & $4(28.57 \%)$ & \\
\hline$>22$ days & $2(3.03 \%)$ & $6(42.86 \%)$ & \\
\hline Hospital cost, median (IQR), dollar & $28,502.82(31,494)$ & $32,042.04(28,492)$ & 0.003 \\
\hline $\mathrm{WBC}, \times 10^{9} / \mathrm{L}$, mean $\pm \mathrm{SD}$ & $10.30 \pm 6.31$ & $10.54 \pm 1.47$ & 0.123 \\
\hline$C R P, m g / L$, mean $\pm S D$ & $73.53 \pm 62.11$ & $71.82 \pm 25.11$ & 0.223 \\
\hline $\mathrm{RBC}, \times 10^{9} / \mathrm{L}$, mean $\pm \mathrm{SD}$ & $3.21 \pm 0.73$ & $3.16 \pm 0.54$ & 0.705 \\
\hline $\mathrm{GPT}, \mathrm{U} / \mathrm{L}$, mean $\pm \mathrm{SD}$ & $46.62 \pm 25.36$ & $44.27 \pm 17.96$ & 0.512 \\
\hline $\mathrm{PCS}, \times 10^{9} / \mathrm{L}$, mean $\pm \mathrm{SD}$ & $126.48 \pm 82.38$ & $122.66 \pm 78.53$ & 0.189 \\
\hline $\mathrm{Cr}$, umol/L, mean $\pm \mathrm{SD}$ & $56.28 \pm 49.98$ & $53.50 \pm 34.59$ & 0.661 \\
\hline
\end{tabular}

$P$ value was calculated between group $A$ and group $B$

$I B D$ inflammatory bowel diseases, DM diabetes mellitus, COPD chronic obstructive pulmonary diseases, $L O S$ length of stay, IQR interquartile range, WBC white blood cell counts, CRP C-reactive protein, $R B C$ red blood cell counts, $P C s$ platelet counts, GPT glutamic-pyruvic transaminase, $C r$ blood urine creatinine ${ }^{a}$ Multiple viscera includes small bowel/colon, duodenum/small bowel or pancreas/duodenum/small bowel

\section{Status of other serum indices}

Table 4 shows the changes of other serum indices measured in our study. For all patient populations, all the laboratory tests presented no significant differences over time, except for some isolated indices. CRP kept decreasing over time in our study and reached a significantly low level at the end of our observational period. The same trend was observed for GPT. PCs in all populations kept increasing to a relatively normal level. In subgroup analysis, changes of serum indices measured in our study shared a similar trend between groups, without any significant differences between Groups A and $\mathrm{B}$.

\section{Discussion}

In the current study, we retrospectively enrolled patients with NTIS admitted at our center and investigated the role of EN therapy in the treatment of NTIS. We observed that 66 out of 80 patients experienced resolution of NTIS after EN therapy. Further, we compared the clinical information between groups in terms of efficacy. A comparison between Groups A and B indicated that 
Table 3 Multivariate analysis of time for initiation of enteral nutrition and other covariates associated with NTIS recovery

\begin{tabular}{|c|c|c|c|c|}
\hline \multirow[t]{2}{*}{ Variables } & \multirow{2}{*}{$\begin{array}{l}\text { Hazard } \\
\text { ratio }\end{array}$} & \multicolumn{2}{|c|}{$95 \% \mathrm{Cl}$} & \multirow{2}{*}{$\begin{array}{l}P \\
\text { value }\end{array}$} \\
\hline & & lower & upper & \\
\hline \multicolumn{5}{|l|}{$\overline{\text { Age }}$} \\
\hline$>48$ & 20.829 & 0.639 & 679.079 & 0.088 \\
\hline$=<48$ & 1.000 & - & - & - \\
\hline \multicolumn{5}{|l|}{ Gender } \\
\hline Male & 1.000 & - & - & - \\
\hline Female & 0.019 & 0.001 & 764.165 & 0.115 \\
\hline \multicolumn{5}{|l|}{ Primary diagnosis } \\
\hline Non- surgical complication & 10.030 & 0.149 & 674.056 & 0.283 \\
\hline Surgical complication & 1.000 & - & - & - \\
\hline \multicolumn{5}{|l|}{ Fistula Location } \\
\hline Single & 1.000 & - & - & - \\
\hline Multiple & 0.037 & 0.001 & 1.093 & 0.058 \\
\hline \multicolumn{5}{|l|}{ Underlying disease } \\
\hline Yes & 1.000 & & & \\
\hline No & 1.405 & 0.104 & 18.898 & 0.798 \\
\hline \multicolumn{5}{|l|}{ APACHE ॥ } \\
\hline$>16$ & 1.000 & & & \\
\hline$=<16$ & 1.461 & 0.869 & 2.456 & 0.152 \\
\hline \multicolumn{5}{|l|}{ FT3 at the baseline } \\
\hline$>3.02$ & 1.000 & - & - & - \\
\hline$=<3.02$ & 0.213 & 0.009 & 5.272 & 0.345 \\
\hline \multicolumn{5}{|c|}{ Time for initiation of enteral nutrition } \\
\hline$=<2$ week & 28.204 & 1.041 & 764.165 & 0.047 \\
\hline$>2$ week & 1.000 & - & - & - \\
\hline
\end{tabular}

FT free thyroxin, $95 \%$ Cl $95 \%$ confidence interval

the time from admission to start of EN therapy was significantly different. Results from logistic regression analysis revealed that the time from admission to start of EN was a significant independent indicator of NTIS outcome. To our knowledge, this is the first study to focus on the potential role of EN in patients with NTIS and enterocutaneous fistula.

The term NTIS is used to describe the deranged TH profile observed in nonthyroidal illnesses that is characterized mainly by decreased serum T3 andor T4 and in some cases suppressed TSH levels [12]. NTIS is a common alteration in thyroid function observed in about $70 \%$ of hospitalized patients, with or without acute systemic illnesses [13]. In this study, the prevalence of NTIS among patients with enterocutaneous fistula was $64.28 \%$ (90/140), which accorded with our previous study, showing the prevalence of this alteration [1].

It was proven that thyroid function abnormalities can occur within hours of acute illness, and the magnitude of these alterations correlates with the severity of the disease. Additionally, the lowest $\mathrm{T} 3$ and $\mathrm{T} 4$ values are associated with decreased survival [2]. Several studies have reported the association between NTIS and poor outcome $[14,15]$. Our previous study also showed that patients with enterocutaneous fistula and NTIS presented worse clinical outcome and prognosis [1].

The etiology of the NTIS has been demonstrated to be multifactorial. It has been suggested that increased levels of endogenous or exogenous glucocorticoids, cytokines and catecholamines are implicated in the dysregulation of thyroid hormones [16-18]. The increased levels of these substances, occurring in conjunction with critical illness and severely hypocaloric diets, favor the conversion of T4 $[19,20]$. Changes in thyroid function are commonly seen as adaptive changes in times of stress. However, consideration has also been given to the possibility that patients who have NTIS may not respond to elevated TSH because of central hypothyroidism secondary to systemic illness [2].

Several studies have examined the efficacy of treating NTIS with thyroxine administration, but the results were inconclusive and controversial [21]. The recovery of thyroid function after administration of EN in patients with NTIS indicates the potential role of EN in reversing NTIS [22]. In this study, we observed an improvement in thyroid function in a cohort of patients with enterocutaneous fistula after EN therapy. A total of $82.50 \%$ $(66 / 80)$ patients experienced resolution of NTIS, indicating a beneficial role of EN in NTIS.

We further compared the general clinical condition between Groups A and B to investigate the differences between patients who recovered from NTIS after EN therapy and those who did not. Based on that comparison, we found that the difference between groups was the time from admission to start of EN therapy. In the logistic analysis, we chose 2 week as the threshold because the median initial time of EN therapy in our patient cohorts is closed to that. We found that patients who received EN therapy within 2 weeks after 2 weeks have a significantly higher chance to recovery from NTIS.

The improvement in thyroid function that we observed after EN therapy in this study may be ascribed to multiple factors. EN therapy may have a direct impact on thyroid function or it may exert an indirect effect by influencing the prognosis of the primary disease. Because the changes of the underlying disease during the treatment were not significantly different between both groups (shown in Table 4), we speculate that EN exerts a direct effect on the improvement of the thyroid function that led to the resolution of NTIS, rather than on underlying diseases among enterocutaneous fistula patients. From this study, we can also conclude that additional thyroxine is not needed in patients under EN therapy with NTIS. Still, a well-designed randomized clinical study is needed to draw a definitive conclusion. 
Table 4 Laboratory tests of all enrolled patients after admission

\begin{tabular}{|c|c|c|c|c|c|c|}
\hline Time & Parameters & All subjects $(N=80)$ & Group A $(N=66)$ & Group B $(N=14)$ & $P$-value ${ }^{a}$ & $P$-value ${ }^{\text {b }}$ \\
\hline \multirow[t]{6}{*}{ Baseline } & $\mathrm{WBC}, \times 10^{9} / \mathrm{L}$, mean $\pm \mathrm{SD}$ & $10.35 \pm 6.52$ & $10.30 \pm 6.31$ & $10.54 \pm 1.47$ & 0.785 & - \\
\hline & $\mathrm{CRP}, \mathrm{mg} / \mathrm{L}$, mean $\pm \mathrm{SD}$ & $72.03 \pm 54.21$ & $73.53 \pm 62.11$ & $71.82 \pm 25.11$ & 0.496 & - \\
\hline & $\mathrm{RBC}, \times 10^{9} / \mathrm{L}$, mean $\pm \mathrm{SD}$ & $3.17 \pm 0.68$ & $3.21 \pm 0.73$ & $3.16 \pm 0.54$ & 0.389 & - \\
\hline & $\mathrm{GPT}, \mathrm{U} / \mathrm{L}$, mean $\pm \mathrm{SD}$ & $45.21 \pm 28.03$ & $46.62 \pm 25.36$ & $44.27 \pm 17.96$ & 0.443 & - \\
\hline & $\mathrm{PCs}, \times 10^{9} / \mathrm{L}$, mean $\pm \mathrm{SD}$ & $124.67 \pm 62.42$ & $126.48 \pm 82.38$ & $122.66 \pm 78.53$ & 0.453 & - \\
\hline & $\mathrm{Cr}$, umol/L, mean $\pm \mathrm{SD}$ & $54.78 \pm 54.11$ & $56.28 \pm 49.98$ & $53.50 \pm 34.59$ & 0.557 & - \\
\hline \multirow[t]{6}{*}{ Week 1} & $\mathrm{WBC}, \times 10^{9} / \mathrm{L}$, mean $\pm \mathrm{SD}$ & $9.87 \pm 5.17$ & $9.89 \pm 5.34$ & $9.35 \pm 3.47$ & 0.745 & 0.466 \\
\hline & $\mathrm{CRP}, \mathrm{mg} / \mathrm{L}$, mean $\pm \mathrm{SD}$ & $42.58 \pm 27.47$ & $43.61 \pm 28.18$ & $40.91 \pm 11.85$ & 0.058 & 0.022 \\
\hline & $\mathrm{RBC}, \times 10^{9} / \mathrm{L}$, mean $\pm \mathrm{SD}$ & $3.19 \pm 0.72$ & $3.20 \pm 0.78$ & $3.18 \pm 0.17$ & 0.177 & 0.597 \\
\hline & $\mathrm{GPT}, \mathrm{U} / \mathrm{L}$, mean $\pm \mathrm{SD}$ & $36.01 \pm 22.28$ & $37.82 \pm 13.51$ & $35.29 \pm 10.83$ & 0.581 & 0.180 \\
\hline & $\mathrm{PCs}, \times 10^{9} / \mathrm{L}$, mean $\pm \mathrm{SD}$ & $141.81 \pm 57.02$ & $143.69 \pm 52.76$ & $140.11 \pm 12.54$ & 0.184 & 0.388 \\
\hline & $\mathrm{Cr}$, umol/L, mean $\pm \mathrm{SD}$ & $52.47 \pm 43.73$ & $54.20 \pm 19.97$ & $51.86 \pm 7.09$ & 0.588 & 0.806 \\
\hline \multirow[t]{6}{*}{ Week 2} & $\mathrm{WBC}, \times 10^{9} / \mathrm{L}$, mean $\pm \mathrm{SD}$ & $10.01 \pm 6.13$ & $10.12 \pm 7.22$ & $9.89 \pm 2.25$ & 0.685 & 0.631 \\
\hline & $\mathrm{CRP}, \mathrm{mg} / \mathrm{L}$, mean $\pm \mathrm{SD}$ & $28.62 \pm 37.38$ & $30.88 \pm 23.48$ & $26.69 \pm 20.87$ & 0.047 & 0.017 \\
\hline & $\mathrm{RBC}, \times 10^{9} / \mathrm{L}$, mean $\pm \mathrm{SD}$ & $3.21 \pm 0.71$ & $3.22 \pm 0.23$ & $3.19 \pm 0.50$ & 0.472 & 0.614 \\
\hline & $\mathrm{GPT}, \mathrm{U} / \mathrm{L}$, mean $\pm \mathrm{SD}$ & $29.12 \pm 12.38$ & $30.24 \pm 16.57$ & $28.59 \pm 14.87$ & 0.841 & 0.158 \\
\hline & $\mathrm{PCS}, \times 10^{9} / \mathrm{L}$, mean $\pm \mathrm{SD}$ & $153.32 \pm 37.32$ & $155.54 \pm 56.77$ & $151.08 \pm 39.52$ & 0.687 & 0.069 \\
\hline & $\mathrm{Cr}$, umol/L, mean $\pm \mathrm{SD}$ & $43.55 \pm 27.31$ & $45.13 \pm 16.47$ & $42.32 \pm 37.54$ & 0.343 & 0.635 \\
\hline \multirow[t]{6}{*}{ Week 3} & $\mathrm{WBC}, \times 10^{9} / \mathrm{L}$, mean $\pm \mathrm{SD}$ & $9.92 \pm 4.38$ & $9.96 \pm 3.82$ & $9.84 \pm 2.87$ & 0.776 & 0.508 \\
\hline & $\mathrm{CRP}, \mathrm{mg} / \mathrm{L}$, mean $\pm \mathrm{SD}$ & $18.52 \pm 10.41$ & $19.13 \pm 13.13$ & $18.23 \pm 9.33$ & 0.214 & 0.012 \\
\hline & $\mathrm{RBC}, \times 10^{9} / \mathrm{L}$, mean $\pm \mathrm{SD}$ & $3.20 \pm 0.85$ & $3.22 \pm 0.93$ & $3.19 \pm 0.12$ & 0.462 & 0.607 \\
\hline & $\mathrm{GPT}, \mathrm{U} / \mathrm{L}$, mean $\pm \mathrm{SD}$ & $21.61 \pm 9.12$ & $22.47 \pm 12.92$ & $20.38 \pm 7.23$ & 0.596 & 0.031 \\
\hline & $\mathrm{PCS}, \times 10^{9} / \mathrm{L}$, mean $\pm \mathrm{SD}$ & $176.66 \pm 50.56$ & $178.89 \pm 67.53$ & $175.12 \pm 24.68$ & 0.295 & 0.045 \\
\hline & $\mathrm{Cr}$, umol/L, mean $\pm \mathrm{SD}$ & $37.93 \pm 15.09$ & $39.55 \pm 10.89$ & $35.23 \pm 27.42$ & 0.493 & 0.431 \\
\hline \multirow[t]{6}{*}{ Week 4} & $\mathrm{WBC}, \times 10^{9} / \mathrm{L}$, mean $\pm \mathrm{SD}$ & $9.16 \pm 5.23$ & $9.20 \pm 7.89$ & $9.12 \pm 3.69$ & 0.823 & 0.383 \\
\hline & $\mathrm{CRP}, \mathrm{mg} / \mathrm{L}$, mean $\pm \mathrm{SD}$ & $14.11 \pm 6.17$ & $14.55 \pm 7.95$ & $19.39 \pm 3.98$ & 0.069 & 0.005 \\
\hline & $\mathrm{RBC}, \times 10^{9} / \mathrm{L}$, mean $\pm \mathrm{SD}$ & $3.22 \pm 0.44$ & $3.25 \pm 0.59$ & $3.20 \pm 0.34$ & 0.406 & 0.621 \\
\hline & $\mathrm{GPT}, \mathrm{U} / \mathrm{L}$, mean $\pm \mathrm{SD}$ & $18.73 \pm 9.91$ & $19.72 \pm 8.26$ & $17.87 \pm 7.40$ & 0.622 & 0.010 \\
\hline & $\mathrm{PCS}, \times 10^{9} / \mathrm{L}$, mean $\pm \mathrm{SD}$ & $187.53 \pm 15.93$ & $189.37 \pm 26.71$ & $185.72 \pm 42.46$ & 0.641 & 0.033 \\
\hline & $\mathrm{Cr}$, umol/L, mean $\pm \mathrm{SD}$ & $35.64 \pm 28.54$ & $37.87 \pm 27.95$ & $33.34 \pm 18.92$ & 0.838 & 0.385 \\
\hline
\end{tabular}

WBC white blood cell counts, CRP C-reactive protein, $R B C$ red blood cell counts, $P C s$ platelet counts, GPT glutamic-pyruvic transaminase, $C r$ blood urine creatinine ${ }^{a} P$ value is compared between group $A$ and group $B$

${ }^{\mathrm{b}} P$ value is compared between the index at varied time point and the same index at the baseline among all subjects

The observational period in our study was limited to 4 weeks because the average hospital stay for patients with enterocutaneous fistula who were admitted to our department was around 4 weeks. Usually, patients with enterocutaneous fistula would be admitted to our department to control infection and maintain homeostasis. When the clinical condition of patients was stable, they would be transferred to another ward. Once a stable condition and homeostasis were achieved, they would return to our department for definitive surgery. Measurement of thyroid function parameters was not available for our cohort after hospital discharge. Thus, this study was limited to 4 weeks of hospitalization.
The present study has several limitations. First, this was just a retrospective observational cohort study from a single medical center. Seasonably, data from different regional hospitals might increase the external validity of our conclusions. Second, as a retrospective study, the validity of our conclusions might increase if the sample size was expanded. In our study, we did not include indices that affected the nutritional status because of the short observational period. We excluded patients with varied comorbidities which limited our patient cohorts. Finally, well-organized randomized, double-blind clinical trials and systematic analysis of the role of EN in enterocutaneous fistula patients with NTIS are needed. 


\section{Conclusions}

In conclusion, this retrospective observational cohort study demonstrated that EN therapy can aid resolution of NTIS in enterocutaneous fistula patients. These findings confirm the benefit of EN in the treatment of enterocutaneous fistula. Further studies are expected to investigate the underlying mechanisms of this effect in the future.

\section{Additional files}

Additional file 1: Table S1. Changes of thyroid function of the whole patient cohort after admission. (DOCX $22 \mathrm{~kb}$ )

Additional file 2: Table S2. Changes of thyroid function after admission. (DOCX $25 \mathrm{~kb})$

\section{Abbreviations}

APACHE II: Acute Physiology and Chronic Health Evaluation Score; Cr: blood urine creatinine; CRP: C - reactive protein; EN: enteral nutrition; FT3: free triiodothyronine; FT4: free thyroxin; GPT: glutamic-pyruvic transaminase; NTIS: the nonthyroidal illness syndrome; PCs: platelet count; RBC: red blood cell count; SD: standard deviation; T3: serum triiodothyronine; T4: thyroxine; TSH: thyroid stimulating hormone; TT3: total triiodothyronine; TT4: total thyroxin; WBC: white blood cell count.

\section{Competing interests}

The authors declare that they have no competing interests.

\section{Authors' contributions}

QW, JR and JL designed the whole study. JR, YZ and JL supervised the whole project. QW, GW and XW performed data analysis. RL, GW, XW, JC, GL, $\mathrm{ZH}$ and HR supervised patient diagnosis and recruitment. QW, JR and GL conducted data analyses and drafted the manuscript. RL, QW and XW participated in the manuscript writing. $R L$ revised the manuscript after the first round revision. All authors critically reviewed the article and approved the final manuscript.

\section{Acknowledgements}

We want to express our thanks to Dr. Kerya Martinez Dunn for his help in revising the manuscript.

Received: 23 June 2015 Accepted: 23 October 2015

Published online: 04 November 2015

\section{References}

1. Han G, Ren J, Liu S, Gu G, Ren H, Yan D, et al. Nonthyroidal illness syndrome in enterocutaneous fistulas. Am J Surg. 2013;206(3):386-92.

2. Adler SM, Wartofsky L. The nonthyroidal illness syndrome. Endocrinol Metab Clin North Am. 2007;36(3):657-72. vi.

3. Meyer S, Schuetz P, Wieland M, Nusbaumer C, Mueller B, Christ-Crain M Low triiodothyronine syndrome: a prognostic marker for outcome in sepsis? Endocrine. 2011:39(2):167-74

4. Brent GA, Hershman JM. Thyroxine therapy in patients with severe nonthyroidal illnesses and low serum thyroxine concentration. J Clin Endocrinol Metab. 1986;63(1):1-8.

5. Acker CG, Singh AR, Flick RP, Bernardini J, Greenberg A, Johnson JP. A trial of thyroxine in acute renal failure. Kidney Int. 2000;57(1):293-8.

6. Acker CG, Flick R, Shapiro R, Scantlebury VP, Jordan ML, Vivas C, et al. Thyroid hormone in the treatment of post-transplant Acute Tubular Necrosis (ATN). Am J Transplant. 2002;2(1):57-61.

7. DuncanPerez-Guisado J, de Haro-Padilla JM, Rioja LF, Derosier LC, de la Torre J. The potential association of later initiation of oral/enteral nutrition on euthyroid sick syndrome in burn patients. Int J Endocrinol. 2013;2013:707360.

8. DeBiasse M, Wilmore D. What is optimal nutritional support? New Horiz. 1994;2(2):122.
9. Michalaki M, Vagenakis AG, Makri M, Kalfarentzos F, Kyriazopoulou V. Dissociation of the early decline in serum T3 concentration and serum IL-6 rise and TNFa in nonthyroidal illness syndrome induced by abdominal surgery. J Clin Endocrinol Metab. 2001;86(9):4198-205.

10. Koenig RJ. Modeling the nonthyroidal illness syndrome. Curr Opin Endocrinol Diabetes Obes. 2008;15(5):466-9.

11. Yuan Y, Ren J, Gu G, Chen J, Li J. Early enteral nutrition improves outcomes of open abdomen in gastrointestinal fistula patients complicated with severe sepsis. Nutr Clin Pract. 2011;26(6):688-94.

12. Pappa TA, Vagenakis AG, Alevizaki M. The nonthyroidal illness syndrome in the non-critically ill patient. Eur J Clin Invest. 2011;41(2):212-20.

13. Chopra IJ. Euthyroid sick syndrome: is it a misnomer? J Clin Endocrinol Metab. 1997:82(2):329-34

14. Bello G. Nonthyroidal illness syndrome and prolonged mechanical ventilation in patients admitted to the ICU. CHEST J. 2009;135(6):1448.

15. Rothwell PM, Lawler PG. Prediction of outcome in intensive care patients using endocrine parameters. Crit Care Med. 1995:23(1):78-83.

16. LoPresti JS, Eigen A, Kaptein E, Anderson KP, Spencer CA, Nicoloff JT. Alterations in 3, 3'5'-triiodothyronine metabolism in response to propylthiouracil, dexamethasone, and thyroxine administration in man. J Clin Invest. 1989:84(5):1650.

17. Kakucska I, Romero L, Clark B, Rondeel J, Qi Y, Alex S, et al. Suppression of thyrotropin-releasing hormone gene expression by interleukin-1-beta in the rat: implications for nonthyroidal illness. Neuroendocrinology. 1994;59(2):129-37.

18. Girvent M, Maestro S, Hernández R, Carajol I, Monné J, Sancho JJ, et al. Euthyroid sick syndrome, associated endocrine abnormalities, and outcome in elderly patients undergoing emergency operation. Surgery. 1998;123(5):560-7.

19. Douyon L, Schteingart DE. Effect of obesity and starvation on thyroid hormone, growth hormone, and cortisol secretion. Endocrinol Metab Clin N Am. 2002;31(1):173-89.

20. Albero R, Sanz A, Playán J. Fasting metabolism. Endocrinol Nutr. 2004;51:139-48.

21. Hama S, Kitaoka T, Shigenobu M, Watanabe A, Imura I, Seno H, et al. Malnutrition and nonthyroidal illness syndrome after stroke. Metabolism. 2005;54(6):699-704.

22. Khorasani EN, Mansouri F. Effect of early enteral nutrition on morbidity and mortality in children with burns. Burns. 2010;36(7):1067-71.

\section{Submit your next manuscript to BioMed Central and take full advantage of:}

- Convenient online submission

- Thorough peer review

- No space constraints or color figure charges

- Immediate publication on acceptance

- Inclusion in PubMed, CAS, Scopus and Google Scholar

- Research which is freely available for redistribution 